\title{
The Effect of Mindfulness-Based Stress Reduction on Resilience of Vulnerable Women at Drop-In Centers in the Southeast of Iran
}

Hamideh Adelian

Kerman University of Medical Sciences

Sedigheh Khodabandeh Shahraki

Kerman University of Medical Sciences

Sakineh Miri

Kerman University of Medical Sciences

Jamileh Farokhzadian ( $\square$ farokhzadian2010@yahoo.com )

Kerman University of Medical Sciences https://orcid.org/0000-0002-9621-3486

Research article

Keywords: Mindfulness-based stress reduction, resilience, vulnerable women, drop-in center

Posted Date: March 17th, 2021

DOI: https://doi.org/10.21203/rs.3.rs-321448/v1

License: (c) (i) This work is licensed under a Creative Commons Attribution 4.0 International License.

Read Full License 


\section{Abstract}

Background: Vulnerable women such as female sex workers and addicted women are among vulnerable groups affecting the social and mental health of societies. They are prone to psychological problems such as anxiety, stress and reduced resilience due to their lifestyles. Mindfulness-based stress reduction (MBSR) is among interventions that many psychotherapists use to treat stress and anxiety. This study aimed to investigate the effectiveness of MBSR on resilience of the vulnerable women.

Methods: The statistical population of this quasi-experimental study consisted of all eligible women referred to the drop-in centers in Kerman in the southeast of Iran. Sixty-three vulnerable women were randomly assigned into two groups of intervention $(n=30)$ and control $(n=33)$. The MBSR intervention was conducted for the intervention group in eight 90-minute sessions. Demographic characteristics questionnaire, and Connor-Davidson resilience scale were used to collect data before and one month after the MBSR intervention.

Results: The results showed that the pre-test score of resilience was not significantly different between the intervention $(53.40 \pm 10.49)$ and the control $(54.5 \pm 9.27)$ groups $(t=0.43, p=0.66)$. The posttest score of resilience in the intervention group $(60.66 \pm 6.71)$ was significantly higher than that of the control group $(53.88 \pm 7.54)(t=3.58, P=0.001)$. Moreover, a comparison of the pretest and posttest scores revealed a significant decrease in resilience of the control group $(t=2.81, p=0.009)$.

Conclusion: Since MBSR intervention increased resilience of the vulnerable women, researchers, managers, counselors, community health nurses and psychiatric nurses are suggested to consider such interventions to promote the health of women, especially vulnerable ones.

\section{Background}

The health of children, family and the community depends on the health of women living in that society. Women are more prone to psychological damage because of the pressures of taking maternal wifely and social roles [1]. Complicated social relationships, poor emotional relationships in families, the young population and the increase of illegal immigration to large cities and suburbanization are among the factors that pave the way for the spread of social deviances, including prostitution and sex work, especially among women. Such a condition threatens the socioeconomic and mental health of families and communities [2]. A systematic review has estimated the prevalence of sex work among over-15-yearold girls between 0.4 and 3.4 in African countries, 0.2 and 2.6 in Asian countries, and 0.1 and 1.4 in European countries. No exact statistics have been published on the rate of sex work in Iran, but 4,00030,000 street-walkers and 200,000-300,000 female sex workers have been reported [3]. Female sex workers, addicts, and the wives of imprisoned men are considered as examples of vulnerable and risky women [2]. Vulnerable women are deprived of emotional support, many of whom are exposed to violence, humiliation, stigma and various physical, mental and verbal discriminations in families and society [4]. Thus, they have been marginalized and stigmatized in society [5]. Wechsberg et al. concluded that 
addicted women were more vulnerable and could not protect themselves sexually [6]. These unpleasant experiences cause anxiety in vulnerable women [7].

Anxiety is a physiological manifestation of stress, which is actually an unpleasant emotional experience and leads to increased activity of the autonomic nervous system [8]. Economic inequalities [9], epidemics of diseases such as coronavirus [10], and addiction [11] are factors affecting stress. Women suffer from anxiety- and stress-related psychiatric disorders twice more than men do, because they are more sensitive to stressful experiences. In addition, men and women are different in neural circuits that affect emotional responses [12].

One of the protective factors against stress is resilience [13]. Some people are very vulnerable to life problems, some other people cope with problems calmly and logically; the difference between the two groups is in their resilience. Resilience means a flexible response to the life stressors [14]. In the theory of Lazarus and Folkman, "stress is an interaction between the person and the environment, whereby individuals appraise environmental demands as outweighing their abilities to meet those demands" [15]. Resilience is the capacity to recover quickly from difficulties and return to the previous level of functioning. In another definition resilience is the ability to mentally or emotionally cope with a crisis or to return to pre-crisis status quickly [16]. Windle (2011) defined resilience as the ability to negotiate, adapt to or manage considerable sources of stress or trauma. Assets and resources of the individuals, their lives and environment facilitate this capacity for adaptation and 'bouncing back' in the face of adversity. Resilience will be experienced differently during the life [17] .

Researchers highlighted that the presence of chronic adversity or psychopathology may interfere with a person's ability to be 'resilient'[18]. Resilience is influenced by health status meaning that mentally ill patients have lower levels of resilience than the general population; resilience can be improved with treatment, so the greater level of resilience is associated with the higher levels of global improvement. The growing focus on health promotion and wellbeing and transition from pathology and problemorientation provide an opportunity to reform the role of resilience in health [19].

Vulnerable women such as female sex workers have low resilience because of sociological causes such as gender, socioeconomic status, poverty and substance abuse [20]. A qualitative study on the resilience of sex workers found that homelessness, drug use and the experience of sexual abuse are negative aspects of resilience. However, protective factors such as education, social support, access to health care [21] and active coping styles increase resilience [22].

Vulnerable women should be trained how to increase their resilience in stressful situations and then respond appropriately to them [23]. Today, mindfulness, one of the methods of stress management, has attracted much attention [24]. Zahra and Riaz (2018) concluded that mindfulness and resilience were statistically significant stress-related factors in students of the University of Gujarat in Pakistan [25]. Managing stress, one learns how to cope with stress according to its biological roots. Stress management skills such as mindfulness-based stress reduction (MBSR) reduce stress and its unpleasant aspects through learning and coping with it is manifested as a coordinated behavior to meet the 
environmental needs [26]. If mindfulness is properly implemented and used, it will complement traditional cognitive-behavioral interventions, increase their effectiveness, and prevent recurrence of stress-related problems [27]. Shapiro et al. define mindfulness as intentional, open-minded, and conscious awareness. This definition consists of three interrelated cores: the first one reflects personal goals and values, and pays attention to the most important things that are happening, the second one is attention as a precondition for clear vision, and the third one is how we pay attention. This does not mean striving to change things, but it does mean striving to connect with them without curious and compassionate judgement [28]. A unique feature of mindfulness is the conscious attention to the stimuli received and adaptive behavior. This approach increases resilience [29].

Researchers considered mindfulness as one of the interventions to increase resilience [30]. Mindfulness teaches us how to pay attention to our issues, including awareness of breathing, negative thoughts and worries about what will happen tomorrow, and re-concentration on the present time and every thought entering our mind is paid attention as it is [31]. Conscious attention causes one to get rid of useless habits and reactions and reaches more useful and appropriate responses [32]. Participants respond to thoughts and somatic feelings, become aware of negative emotions such as anxiety, and increase their coping skills by focusing on the source of stress during mindfulness sessions [33]. There are many hypotheses about the mechanisms of mental concentration in mindfulness, one of which is that exposure to or tendency to experience difficult emotions (such as anxiety, stress, anger), awareness and observation of these emotions allow people to better cope with and regulate difficult emotions. Another hypothesis is that awareness of thoughts and somatic feelings helps people cope with stress and increase their resilience [34]. Numerous studies have examined the effectiveness of mindfulness-based interventions on the psychological variables of vulnerable groups. For example, Sancho et al. (2018) in a systematic review considered mindfulness-based interventions effective in the treatment of substance and behavioral addictions and suggested that future research should focus on longer follow-ups, young and vulnerable populations [35]. Other studies also confirmed the effect of the MBSR on participants' resilience in vulnerable groups [32, 36-40].

Owing to the fact that the vulnerable women such as female sex workers experience a lot of stress due to social harms, which lead to their psychological social problems and decrease their resilience, it is necessary to conduct the mental health interventions developed for them. Although MBSR contains valuable lessons about interpersonal issues, little research has been found on this vulnerable group. This study aimed to investigate the effect of MBSR on resilience of vulnerable women referred to the drop-in center. The following hypothesis was examined:

Vulnerable women who attended an 8-week MBSR intervention would demonstrate enhanced resilience and its subscales, compared with those in control group.

\section{Methods}

\section{Study design and setting}


This quasi-experimental study was performed with two groups and pretest and posttest design to examine the effect of MBSR training on resilience of vulnerable women. The research settings were two drop-in centers, one affiliated to Kerman University of Medical Sciences and the other affiliated to the Welfare Organization located in Kerman, the largest city in southeastern Iran. Establishment of a drop-in center (DIC) can provide health services, reduce harm and increase the mental health of female sex workers. These centers have been established in more than 38 densely populated areas of Iran, especially in the provinces by universities of medical sciences and the cooperation of non-governmental organizations affiliated with the Welfare Organization [41]. DICs are the primary source of assistance for women who have left home. The centers help clients meet their health needs such as counseling, mental health, behavioral care and midwifery examinations, health education and promotion, shelter and food. The purpose is to reduce the socioeconomic and health consequences and substance abuse, etc. Women who use these centers are less exposed to sexual victimization or criminal risks such as drug trafficking [42].

\section{Study population and sampling}

The statistical population in this study was all vulnerable women who referred to drop-in centers in Kerman in $2020(\mathrm{~N}=140)$ : center No. 1 affiliated to the welfare organization with 40 clients and center No. 2 affiliated to the University of Medical Sciences with 100 clients.

First, the sample size was calculated to be 60 by using the sample size formula, and then, 70 vulnerable women were included in the study by taking into account about 15-percent dropout probability and an increase in the study power. For better access to women and more coordination, the intervention group was selected from the center No. 1 and the control group was selected from the center No. 2. We first prepared a list of clients of both centers and selected 35 people from each center using a random number table. In total, 70 women were selected from both centers. It should be noted that both centers had the same conditions and provided similar services to the clients.

Inclusion criteria included physical health and no severe mental disorders, no severe learning disabilities, sufficient time for mindfulness practice, age over 18, and no history of participation in MBSR sessions or similar interventions. Exclusion criteria included the participant's unwillingness to continue MBSR sessions and absenteeism in more than two sessions, significant psychological and emotional changes during the study, such as the death of a family member.

\section{Measurements}

Two instruments were used to collect data. The demographic information questionnaire collected information on occupation, age, marital status, education, history of being imprisoned, family support, friends' support, insurance coverage, number of children, and type of vehicle used.

The Persian version of Connor-Davidson Resilience Scale (CD-RISC) was used in our study to assess the resilience. The CD-RISC comprises of 25 items, each rated on a five-point scale (0-4) with higher scores 
reflecting greater resilience (Additional File 1). The reliability of the original CD-RISC-25 was assessed through test-retest correlation $(r=0.87)$ and the internal consistency $(a=0.89)$ in the studies conducted on American participants. Its convergent validity showed that the scale had positive correlations with psychological variables such as hardiness, social support, and negative correlations with perceived stress, degree of disability, and stress vulnerability [19]. Iranian researchers determined psychometric properties of CD-RISC-25 by permission of its authors, and for its reliability of the reported Cronbach's alpha of 0.94 . Exploratory factor analysis and principal factor analysis have been used to determine its validity [43].

\section{Data collection and intervention}

At the beginning of the study, the participants completed demographic information questionnaire and CDRISC. The intervention and control groups simultaneously recompleted the questionnaires one month after the last session of MBSR. Participants in the intervention group were divided into 2 groups of 17 to 18. They received the MBSR in 90-minute sessions for 8 weeks (1 session a week; table 1). A clinical psychologist skillful in MBSR prepared the MBSR intervention package, and she trained it. The participants in the control group received the routine care such as counseling, mental health, behavioral care and midwifery examinations, health education and promotion, shelter and food. No training was provided for the control group during the study.

Table 1: The Intervention Protocol.

\begin{tabular}{|c|c|}
\hline $\begin{array}{l}\text { Session } \\
1\end{array}$ & $\begin{array}{l}\text {-Short introduction to the program, confidentiality and privacy, introduction of participants, } \\
\text { raisin eating practice (introduction to mindfulness meditation) }\end{array}$ \\
\hline $\begin{array}{l}\text { Session } \\
2\end{array}$ & $\begin{array}{l}\text {-Body scan meditation, discussion of barriers to exercise, introduction of seated } \\
\text { meditation with awareness of breathing, breath-work, sitting, yoga, and eating meditation }\end{array}$ \\
\hline $\begin{array}{l}\text { Session } \\
3\end{array}$ & -Seated meditation with a focus on breathing and body, calendar of unpleasant events \\
\hline $\begin{array}{l}\text { Session } \\
4\end{array}$ & $\begin{array}{l}\text {-Seated meditation with focusing on breathing, body senses, sounds and thoughts, group } \\
\text { exploration, conscious walking }\end{array}$ \\
\hline $\begin{array}{l}\text { Session } \\
5\end{array}$ & $\begin{array}{l}\text {-Reacting and responding to stress, guided seated meditation, discussing people's } \\
\text { observations of reacting to stressful events during the week, discussing life-changing } \\
\text { events and their relationships with health, discussing mindful walking, finishing class with } \\
\text { a seated meditation, gentle stretching, group discussion }\end{array}$ \\
\hline $\begin{array}{l}\text { Session } \\
6\end{array}$ & $\begin{array}{l}\text {-Practice of alternative moods, thoughts and perspectives, short seated meditation, } \\
\text { sharing feelings for } 30 \mathrm{~min}\end{array}$ \\
\hline $\begin{array}{l}\text { Session } \\
7\end{array}$ & -Four-dimensional meditation, a discussion of the pleasant and unpleasant life events \\
\hline $\begin{array}{l}\text { Session } \\
8\end{array}$ & -Body scan meditation, breathing exercises, use of what has been learned so far \\
\hline
\end{tabular}




\section{Statistical analysis}

SPSS 21, as well as descriptive (frequency, percentage, mean and standard deviation) and inferential statistics (independent samples $t$-test, paired $t$-test, chi-square test, and the analysis of covariance) were used for data analysis. The significance level was $\leq 0.05$.

\section{Results}

\section{Demographic information}

Of 70 participants, 30 women in the intervention group and 33 women in the control group completed the questionnaires. Five individuals from the intervention group were excluded because of not completing the MBSR sessions and post-intervention questionnaires and two individuals from the control group were excluded because of incomplete questionnaires ( $90 \%$ response rate).

The results showed that most of the women in the intervention and control groups were housewifery $(83.3 \%, 87.9 \%)$, married $(36.7 \%, 63.6 \%)$ with elementary level of education $(40.00 \%, 33.3 \%) .41 .4 \%$ of the participants in the intervention group were $40-50$ years old, and $59.4 \%$ of the participants in the control group were 30-40 years old. Table 2 presents additional demographic information of participants in the intervention and control groups. Furthermore, there were no differences in the baseline measures of demographic variables except for marital status. 
Table 2

Comparison of demographic information of intervention and control groups

\begin{tabular}{|c|c|c|c|c|c|c|c|}
\hline \multirow[t]{2}{*}{ Variables } & \multirow{2}{*}{$\begin{array}{l}\text { groups } \\
\text { Categories }\end{array}$} & \multicolumn{2}{|c|}{$\begin{array}{l}\text { Intervention } \\
\text { group }\end{array}$} & \multicolumn{4}{|c|}{$\begin{array}{l}\text { Control } \\
\text { group }\end{array}$} \\
\hline & & $\mathrm{n}$ & $\%$ & $\mathrm{n}$ & $\%$ & $x^{2}$ & $\mathrm{p}$ \\
\hline \multirow[t]{4}{*}{ Occupation } & Housewife & 26 & 86.70 & 29 & 87.90 & 5.96 & 0.20 \\
\hline & Employed & 4 & 13.30 & 1 & 3.00 & & \\
\hline & Self-employed & 0 & 0 & 1 & 3.00 & & \\
\hline & Retired & 0 & 0 & 2 & 6.10 & & \\
\hline \multirow[t]{4}{*}{ Age groups } & $20-30$ & 2 & 6.60 & 3 & 9.00 & 2.93 & 0.40 \\
\hline & $30-40$ & 11 & 36.60 & 19 & 57.80 & & \\
\hline & $40-50$ & 13 & 43.30 & 8 & 24.20 & & \\
\hline & $50-60$ & 4 & 13.50 & 3 & 9.00 & & \\
\hline \multirow[t]{2}{*}{ Family support } & Yes & 13 & 43.30 & 21 & 63.60 & 2.60 & 0.11 \\
\hline & no & 17 & 56.70 & 12 & 36.40 & & \\
\hline \multirow[t]{2}{*}{ Friends' support } & Yes & 10 & 33.30 & 11 & 33.30 & 00 & \\
\hline & no & 20 & 66.70 & 22 & 66.70 & & \\
\hline \multirow[t]{3}{*}{ Education level } & Elementary & 12 & 40.00 & 11 & 33.30 & 3.15 & 0.37 \\
\hline & High school & 10 & 33.30 & 9 & 27.30 & & \\
\hline & Diploma & 8 & 26.70 & 13 & 39.40 & & \\
\hline \multirow[t]{4}{*}{ Marital status } & Single & 0 & 0 & 3 & 9.10 & 96.9 & 0.01 \\
\hline & Married & 11 & 36.70 & 21 & 63.60 & & \\
\hline & Widowed & 8 & 26.60 & 5 & 15.20 & & \\
\hline & divorced & 11 & 36.70 & 4 & 12.10 & & \\
\hline \multirow{2}{*}{$\begin{array}{l}\text { History of being } \\
\text { imprisoned }\end{array}$} & Yes & 11 & 36.70 & 6 & 18.20 & 3.42 & 0.18 \\
\hline & no & 19 & 63.30 & 27 & 81.80 & & \\
\hline \multirow[t]{3}{*}{ Children No. } & 0 & 2 & 6.08 & 7 & 21.90 & 2.73 & 0.25 \\
\hline & 1 & 8 & 26.6 & 7 & 21.90 & & \\
\hline & $\geq 2$ & 20 & 66.6 & 19 & 56.20 & & \\
\hline
\end{tabular}




\begin{tabular}{|llllllll|}
\hline Variables & groups & \multicolumn{2}{l}{$\begin{array}{l}\text { Intervention } \\
\text { group }\end{array}$} & \multicolumn{4}{l|}{$\begin{array}{l}\text { Control } \\
\text { group }\end{array}$} \\
\hline Type of vehicle & personal & 1 & 3.30 & 6 & 18.20 & 3.53 & 0.17 \\
& public transportation & 22 & 73.30 & 21 & 63.60 & & \\
& None & 7 & 23.30 & 6 & 18.20 & & \\
\hline Insurance coverage & Social security & 9 & 30.00 & 8 & 24.20 & 4.64 & 0.46 \\
& Relief Foundation & 3 & 10.00 & 0 & 0 & & \\
& Rural & 4 & 13.30 & 4 & 12.10 & & \\
& Health & 6 & 20.00 & 6 & 18.10 & & \\
& Therapeutic & 1 & 3.40 & 2 & 6.30 & & \\
& None & 7 & 23.30 & 13 & 39.30 & & \\
\hline
\end{tabular}

Table 3 shows the level of resilience and its dimensions in both groups before and after the intervention. The total score of resilience in the intervention group increased statistically significant at the posttest $(t=-7.81, p=0.001)$. A comparison of the pretest and posttest scores in the control group revealed a significant decrease in resilience $(t=2.81, p=0.009)$.

In the pretest phase, no statistically significant difference in the scores of resilience between the intervention (53.40 \pm 10.49$)$ and control $(54.5 \pm 9.27)$ groups $(t=0.43, p=0.66)$. Moreover, in the posttest phase, a statistically significant difference was observed between the intervention $(60.66 \pm 6.71)$ and control (53.88 \pm 7.54$)$ groups in total score of the resilience $(t=3.58, p=0.001)$.

Covariance analysis test was used to confirm the results of Table 3. The results showed by controlling the impact of pretest on the resilience, there were statistically significant differences between the control and intervention groups in the total posttest scores of resilience and its dimensions (Table 4). 
Table 3

Comparison of scores of resilience between the control and intervention groups before and after the MBSR program

\begin{tabular}{|c|c|c|c|c|c|c|}
\hline Variable & $\begin{array}{l}\text { Time } \\
\text { Groups }\end{array}$ & $\begin{array}{l}\text { Pretest } \\
\text { Mean } \\
\pm \text { SD }\end{array}$ & $\begin{array}{l}\text { Posttest } \\
\text { Mean } \pm \\
\text { SD }\end{array}$ & $\begin{array}{l}\text { Mean } \\
\text { difference }\end{array}$ & $\begin{array}{l}\text { Paired- } \\
\text { t test }\end{array}$ & $\begin{array}{l}\mathrm{P} \\
\text { value }\end{array}$ \\
\hline \multirow{5}{*}{$\begin{array}{l}\text { Personal competence, high } \\
\text { standards, and tenacity }\end{array}$} & Intervention & $\begin{array}{l}16.36 \\
+484\end{array}$ & $\begin{array}{l}20.76 \pm \\
286\end{array}$ & 4.40 & 8.93 & 0.001 \\
\hline & Control & & & \multirow[t]{4}{*}{-0.25} & \multirow[t]{4}{*}{2.70} & \multirow[t]{4}{*}{0.01} \\
\hline & $\begin{array}{l}\text { Independent } \\
\text { t-test }\end{array}$ & $\begin{array}{l}16.60 \\
\pm 5.40\end{array}$ & $\begin{array}{l}16.35 \pm \\
4.49\end{array}$ & & & \\
\hline & P value & 0.184 & 4.49 & & & \\
\hline & & 0.85 & 0.001 & & & \\
\hline \multirow{5}{*}{$\begin{array}{l}\text { Trust in one's instincts, } \\
\text { tolerance of negative affect, } \\
\text { and strengthening of the } \\
\text { effects of stress }\end{array}$} & Intervention & $\begin{array}{l}11.63 \\
\pm 4.55\end{array}$ & $\begin{array}{l}14.26 \pm \\
3.07\end{array}$ & \multirow{5}{*}{$\begin{array}{l}2.63 \\
-0.66\end{array}$} & \multirow{5}{*}{$\begin{array}{l}7.18 \\
1.69\end{array}$} & \multirow{5}{*}{$\begin{array}{l}0.001 \\
0.10\end{array}$} \\
\hline & Control & & $1127+$ & & & \\
\hline & $\begin{array}{l}\text { Independent } \\
\text { t-test }\end{array}$ & \pm 4.50 & 4.05 & & & \\
\hline & \multirow{2}{*}{$P$ value } & 0.26 & 3.20 & & & \\
\hline & & 0.79 & 0.002 & & & \\
\hline \multirow{5}{*}{$\begin{array}{l}\text { The positive acceptance of } \\
\text { change, and secure } \\
\text { relationships }\end{array}$} & Intervention & $\begin{array}{l}10.03 \\
\pm 1.32\end{array}$ & $\begin{array}{l}12.23 \pm \\
2.40\end{array}$ & \multirow{5}{*}{$\begin{array}{l}2.20 \\
-0.46\end{array}$} & \multirow{5}{*}{$\begin{array}{l}6.33 \\
1.00\end{array}$} & \multirow{5}{*}{$\begin{array}{l}0.001 \\
0.32\end{array}$} \\
\hline & Control & & & & & \\
\hline & Independent & \pm 2.19 & 2.05 & & & \\
\hline & \multirow{2}{*}{$P$ value } & 0.33 & -4.32 & & & \\
\hline & & 0.74 & 0.001 & & & \\
\hline \multirow[t]{5}{*}{ Control } & Intervention & $\begin{array}{l}6.60 \pm \\
263\end{array}$ & $8.20 \pm$ & 1.60 & 5.44 & 0.001 \\
\hline & Control & & & \multirow[t]{4}{*}{0.14} & \multirow[t]{4}{*}{0.13} & \multirow[t]{4}{*}{0.89} \\
\hline & $\begin{array}{l}\text { Independent } \\
\text { t-test }\end{array}$ & 2.68 & 2.33 & & & \\
\hline & \multirow{2}{*}{$P$ value } & 0.55 & 2.06 & & & \\
\hline & & 0.58 & 0.04 & & & \\
\hline \multirow[t]{5}{*}{ Spiritual influences } & Intervention & $\begin{array}{l}6.56 \pm \\
1.25\end{array}$ & $\begin{array}{l}7.40 \pm \\
0.77\end{array}$ & \multirow{5}{*}{$\begin{array}{l}0.84 \\
-0.21\end{array}$} & 7.81 & 0.001 \\
\hline & Control & & & & \multirow[t]{4}{*}{2.11} & \multirow{4}{*}{0.04} \\
\hline & $\begin{array}{l}\text { Independent } \\
\text { t-test }\end{array}$ & 1.26 & 1.16 & & & \\
\hline & \multirow{2}{*}{$P$ value } & -0.79 & 3.14 & & & \\
\hline & & 0.43 & 0.003 & & & \\
\hline
\end{tabular}




\begin{tabular}{|c|c|c|c|c|c|c|}
\hline Variable & $\begin{array}{l}\text { Time } \\
\text { Groups }\end{array}$ & $\begin{array}{l}\text { Pretest } \\
\text { Mean } \\
\pm \text { SD }\end{array}$ & $\begin{array}{l}\text { Posttest } \\
\text { Mean } \pm \\
\text { SD }\end{array}$ & $\begin{array}{l}\text { Mean } \\
\text { difference }\end{array}$ & $\begin{array}{l}\text { Paired- } \\
\text { t test }\end{array}$ & $\begin{array}{l}\mathrm{P} \\
\text { value }\end{array}$ \\
\hline \multirow[t]{5}{*}{ Resilience total } & Intervention & $\begin{array}{l}53.40 \\
\pm\end{array}$ & \multirow[t]{2}{*}{$\begin{array}{l}60.66 \pm \\
6.71\end{array}$} & & -7.81 & 0.001 \\
\hline & Control & 10.49 & & -0.62 & 2.81 & 0.009 \\
\hline & $\begin{array}{l}\text { Independent } \\
\text { t-test }\end{array}$ & $\begin{array}{l}54.50 \\
\pm 9.27\end{array}$ & $\begin{array}{l}53.88 \pm \\
7.54\end{array}$ & & & \\
\hline & \multirow{2}{*}{$P$ value } & -0.43 & \multirow{2}{*}{$\begin{array}{l}3.58 \\
0.001\end{array}$} & & & \\
\hline & & 0.66 & & & & \\
\hline
\end{tabular}


Table 4

Summary of covariance analysis for the two groups of control and intervention

\begin{tabular}{|c|c|c|c|c|c|}
\hline Variable & & df & $\begin{array}{l}\text { Mean } \\
\text { square }\end{array}$ & $F$ & p-value \\
\hline \multirow[t]{7}{*}{$\begin{array}{l}\text { personal competence, high standards, and } \\
\text { tenacity }\end{array}$} & $\begin{array}{l}\text { Corrected } \\
\text { model }\end{array}$ & 4 & 222.53 & 68.07 & $<0.001$ \\
\hline & Intercept & 1 & 75.66 & 23.14 & $<0.001$ \\
\hline & Pre test & 1 & 0.012 & 0.004 & 0.952 \\
\hline & Marriage & 1 & 6.09 & 1.86 & 0.178 \\
\hline & time & 1 & 593.6 & 181.59 & $<0.001$ \\
\hline & Group & 1 & 270.78 & 82.83 & $<0.001$ \\
\hline & Error & 55 & 3.26 & & \\
\hline \multirow{7}{*}{$\begin{array}{l}\text { trust in one's instincts, } \\
\text { tolerance of negative affect, and strengthening } \\
\text { of the effects of stress }\end{array}$} & $\begin{array}{l}\text { Corrected } \\
\text { model }\end{array}$ & 4 & 188.72 & 90.91 & $<0.001$ \\
\hline & Intercept & 1 & 101.67 & 48.97 & $<0.001$ \\
\hline & Pre test & 1 & 6.59 & 3.17 & 0.08 \\
\hline & Marriage & 1 & 8.59 & 4.13 & 0.04 \\
\hline & time & 1 & 606.67 & 292.24 & $<0.001$ \\
\hline & Group & 1 & 163.29 & 78.66 & $<0.001$ \\
\hline & Error & 55 & 2.07 & & \\
\hline \multirow[t]{7}{*}{$\begin{array}{l}\text { The positive acceptance of change, and secure } \\
\text { relationships }\end{array}$} & $\begin{array}{l}\text { Corrected } \\
\text { model }\end{array}$ & 4 & 35.06 & 21.48 & $<0.001$ \\
\hline & Intercept & 1 & 21.39 & 13.10 & $<0.001$ \\
\hline & Pre test & 1 & 0.097 & 0.06 & 0.80 \\
\hline & Marriage & 1 & 4.81 & 2.95 & 0.09 \\
\hline & time & 1 & 66.93 & 41.01 & $<0.001$ \\
\hline & Group & 1 & 58.73 & 35.99 & $<0.001$ \\
\hline & Error & 55 & 1.63 & & \\
\hline \multirow[t]{3}{*}{ Control } & $\begin{array}{l}\text { Corrected } \\
\text { model }\end{array}$ & 4 & 43.56 & 32.73 & $<0.001$ \\
\hline & Intercept & 1 & 17.32 & 13.02 & $<0.001$ \\
\hline & Pre test & 1 & 0.84 & 0.63 & 0.43 \\
\hline
\end{tabular}




\begin{tabular}{|c|c|c|c|c|c|}
\hline \multicolumn{2}{|l|}{ Variable } & \multirow{2}{*}{$\begin{array}{c}\mathbf{d f} \\
1\end{array}$} & \multirow{2}{*}{$\begin{array}{l}\text { Mean } \\
\text { square }\end{array}$} & \multirow{2}{*}{$\begin{array}{l}\mathbf{F} \\
0.15\end{array}$} & \multirow{2}{*}{$\begin{array}{l}\text { p-value } \\
0.70\end{array}$} \\
\hline & Marriage & & & & \\
\hline & time & 1 & 153.41 & 115.28 & $<0.001$ \\
\hline & Group & 1 & 18.97 & 14.26 & $<0.001$ \\
\hline & Error & 55 & 1.33 & & \\
\hline \multirow[t]{7}{*}{ Spiritual influences } & $\begin{array}{l}\text { Corrected } \\
\text { model }\end{array}$ & 4 & 11.28 & 29.71 & $<0.001$ \\
\hline & Intercept & 1 & 11.28 & 29.72 & $<0.001$ \\
\hline & Pre test & 1 & 0.93 & 2.47 & 0.12 \\
\hline & Marriage & 1 & 0.44 & 1.16 & 0.28 \\
\hline & time & 1 & 32.51 & 85.63 & $<0.001$ \\
\hline & Group & 1 & 11.35 & 29.90 & $<0.001$ \\
\hline & Error & 55 & 0.38 & 69.41 & \\
\hline \multirow[t]{7}{*}{ Resilience total } & $\begin{array}{l}\text { Corrected } \\
\text { model }\end{array}$ & 4 & 725.19 & 54.54 & $<0.001$ \\
\hline & Intercept & 1 & 569.79 & 0.99 & $<0.001$ \\
\hline & Pre test & 1 & 10.40 & 0.38 & 0.32 \\
\hline & Marriage & 1 & 3.99 & 210.15 & 0.54 \\
\hline & time & 1 & 2195.50 & 79.60 & $<0.001$ \\
\hline & Group & 1 & 831.6 & & $<0.001$ \\
\hline & Error & 55 & 10.44 & & \\
\hline
\end{tabular}

\section{Discussion}

This study examined the effect of MBSR on resilience of vulnerable women. The present results supported our hypothesis and the posttest resilience score of the intervention group increased significantly. Consistent with the current study, previous studies reported higher posttest resilience scores in participants of the intervention group. For example, Nila et al. in Germany [36], Hwang et al. [37] in Korea, and Galante et al. [45] reported the increased level of resilience in general populations and students of Cambridge University after the intervention and even in the follow-up stages. Numerous studies also in Iran confirmed the effect of mindfulness-based interventions on resilience of vulnerable populations, including the wives of veterans with amputations [38], patients with systemic lupus erythematosus [39], mothers of children with cancer [47] and war veterans [48]. In addition, studies on the 
wives of men with schizophrenia [40], female victims of domestic violence [49], wives of veterans with psychiatric diseases [50], female-headed households [32], mothers of children with learning disabilities [51] and husband's infidelity achieved similar results [52]. The results of these studies are similar to the present study because the interventions are essentially the same and are performed on vulnerable groups that have little resilience for various reasons such as social, psychological and supportive conditions. On the other hand, these people are often neglected in society and receive little training in this field. This intervention may motivate and encourage them to learn and improve resilience. Researchers emphasize that when a person with negative thoughts becomes aware of the symptoms of bad thoughts in educational programs, he/she can cope with problems better and increase her/his tolerance. MBSR allows people to experience many positive emotions and adapt well to new social situations. Therefore, individuals can gain widespread social support. On the other hand, positive emotions are an appropriate response to emotional, social and material needs and ultimately lead to resilience [48]. Our results suggest that in spite of critical factors and high pressures, resilient individuals can improve their social capacities and overcome problems. Vulnerable people must therefore be trained to increase their resilience and to cope with risky situations with greater bio-psychological and social balance.

In contrast, Dyrbye et al. (2017) observed no change in resilience of medical students in a study. According to the researchers, the reason was that the study was quasi-experimental without a control group, and medical students were under a lot of stress. In addition to the mindfulness program, other programs were suggested to increase their resilience [53]. Another study showed a direct and poor correlation between mindfulness and resilience in high school students with poor socioeconomic conditions in Turkey. The reasons for the difference between this study and the present study were different type of study, sample and data collection tools. This study was correlational and adolescents' resilience and mindfulness were studied. In addition, the research population was different in gender, age and cultural and geographical status [54].

The results of our study showed that the mean posttest resilience score in the control group was significantly lower than the pretest score. One of the reasons is that post-intervention evaluation was coincided with the outbreak of coronavirus, which has affected the level of communication with friends, family and healthcare providers. Low level of communication has reduced social support and the economic conditions resulting from quarantine have reduced the rate of resilience. Participants in the control group were living in rented houses in suburbs with no insurance coverage, so they were raped and physically abused compared with the participants in the intervention group. In agreement with our results, several studies reported that the resilience score in the control group decreased after MBSR intervention $[48,49,52]$. In addition, some studies reported that the resilience score of women in the control group increased after the intervention $[40,51]$. The results of this study highlight the importance of initiative approaches to promote resilience of the vulnerable women. Vulnerable women experience many stressful situations during their lives. Inability to cope with and manage these situations can influence vulnerable women, reduce their general health and increase their psychological problems. Therefore, MBSR can increase vulnerable women' coping skills in stressful situations, so they have better control on their life events and face the challenging situations with more resilience. 


\section{Limitations}

The present study included some limitations. First, two different centers were used for allocation of the intervention and control groups to prevent the treatment diffusion that could endanger the internal validity of the study and influence the behavior of the control group. However, the researchers confirmed that both groups were similar at the beginning of the study and they had enough distance from each other [55]. Second, this study was performed only in drop-in centers in southeastern Iran with a small sample size and two measurement steps. Therefore, we recommend future researchers to conduct similar studies in other settings with larger sample sizes and examine the effects of MBSR training over several follow-ups, such as 2-6 months.

\section{Conclusions}

The results showed that MBSR intervention significantly increased the resilience of vulnerable women. Resilience has a mental and cognitive aspect, and MBSR is a learning process that can change the attitudes, cognitions, behaviors and interactions of vulnerable people, especially women and make them less stressed and more resilient. A lot of stress and low resilience can greatly damage physical, psychological, social, spiritual health of vulnerable women. Since MBSR is an inexpensive, easy-to-use and practical method and affects the resilience of these vulnerable women, the healthcare team, especially community nurses (including community health nurses and psychiatric nurses) are recommended to develop their knowledge and skills about this intervention. Psychologists and counselors should help them implement such interventions for vulnerable groups and promote community health. This method should be used in diverse domains of healthcare. Nurse managers, decision-makers, nurse educators, and authorities of clinical settings should provide MBSR to make vulnerable groups more resilient. Future research should examine the effect of MBSR on other variables such as anxiety, stress and social adjustment in different cultures and contexts.

\section{Abbreviations}

CD-RISC: Connor-Davidson Resilience scale

MBSR: Mindfulness-based stress reduction

DIC: drop-in center

\section{Declarations}

\section{Acknowledgments}

The authors appreciate the drop-in centers officials and all vulnerable women who generously participated in this study. We also appreciate Mrs. mozhgan.rabani, the clinical psychologists, who 
cooperated with help research team develop the content and education of the MBSR program in this study.

\section{Authors' contributions}

HA, SM, SKH, and JF contributed to conceiving and designing the research. The data were collected, analyzed, and interpreted by JF, HA, SM, and SKH. HA, SM, SKH, and JF contributed equally to writing and revising the manuscript and approved the final manuscript.

\section{Funding}

This research received no specific grant from any funding agency in the public, commercial, or not-forprofit sectors.

\section{Availability of data and materials}

The data are available upon request to the corresponding author after signing appropriate documents in line with ethical application and the decision of the Ethics Committee.

\section{Ethics approval and consent to participate}

Ethical committee of Kerman University of Medical Sciences has approved the present study with the code 98000613 and ethics No. IR.KMU.REC.1398.559. Other ethical criteria included written consent to enter the study and withdraw the study whenever participants were willing. Special codes were assigned to each of the participants to ensure the information confidentiality. The results were provided to the participants and authorities in DICs upon their requests.

\section{Consent for publication}

Not applicable.

\section{Competing interests}

The authors declare that they have no competing interests

\section{ORCID iD}

Jamileh Farokhzadian, http://orcid.org/0000-0002-9621-3486

\section{References}

1. Shayan A, Masoumi SZ, Kaviani M. The relationship between wife abuse and mental health in women experiencing domestic violence referred to the forensic medical center of shiraz. J Educ Community Health. 2015;1(4):51-7. 
2. Rahmani K, Bidarpour F, Moradi G, Karimi M, Mollashi M. Women's experiences of selling from highrisk behaviors and the causes of these behaviors from their point of view and the authorities of the counseling center: a qualitative study. Journal of Qualitative Research in Health Sciences. 2017;5(4):326-36.

3. Love R. Street level prostitution: A systematic literature review. Issues Ment Health Nurs. 2015;36(8):568-77.

4. Alimohammadi N, Baghersad Z, Boroumandfar Z. Vulnerable Women's Self-Care Needs in Knowledge, Attitude and Practice Concerning Sexually Transmitted Diseases. International journal of community based nursing midwifery. 2016;4(3):219.

5. Khodabakhshi Koolaee A, Damirchi F. Comparing quality of life among female sex workers with and without addiction. Journal of Client-Centered Nursing Care. 2016;2(4):201-6.

6. Wechsberg WM, Jewkes R, Novak SP, Kline T, Myers B, Browne FA, Carney T, Lopez AAM, Parry C. A brief intervention for drug use, sexual risk behaviours and violence prevention with vulnerable women in South Africa: a randomised trial of the Women's Health CoOp. BMJ open 2013, 3(5).

7. Kyia S, Harfateh ZZ. The Effectiveness of Stress Management Training on Cognitive-Behavioral Disorders and Quality of Life for Female Heads of Households. Sociol Educ. 2018;8(8):94-110.

8. Keykhawi S, Dadfar R, Moghaddam RH. The effect of music therapy on reducing addiction, anxiety and depression in drug addicts. Quarterly Journal of Medical History. 2012;4(13):107-25.

9. Dms y, Da. p: stress psychology. tehran: timurzadeh publications. tabib publication; 2013.

10. Shahyad S, Mohammadi MT. Psychological Impacts of Covid-19 Outbreak on Mental Health Status of Society Individuals: A Narrative Review. Journal of Military Medicine. 2020;22(2):184-92.

11. Ip. M. The mindful path to addiction recovery. Esfehan: negar khane; 2016.

12. Maeng LY, Milad MR. Sex differences in anxiety disorders: interactions between fear, stress, and gonadal hormones. Hormones behavior. 2015;76:106-17.

13. Serra L, Contador I, Fernández-Calvo B, Ruisoto P, Jenaro C, Flores N, Ramos F, Rivera-Navarro J. Resilience and social support as protective factors against abuse of patients with dementia: A study on family caregivers. Int J Geriatr Psychiatry. 2018;33(8):1132-8.

14. Aslanifar $\mathrm{E}$, Bahrami $\mathrm{H}$, Asadzadeh $\mathrm{H}$. The effectiveness of positive group therapy in promoting resilience and self-esteem of divorced women. Cultural-Educational Quarterly of Women Family. 2018;42(12):97-111.

15. Steinhardt M, Dolbier C. Evaluation of a resilience intervention to enhance coping strategies and protective factors and decrease symptomatology. Journal of American college health. 2008;56(4):445-53.

16. Somasundaram RO, Devamani KA. A comparative study on resilience, perceived social support and hopelessness among cancer patients treated with curative and palliative care. Indian J Palliat Care. 2016;22(2):135. 
17. Windle G. What is resilience? A review and concept analysis. Reviews in clinical gerontology. 2011;21(2):152.

18. Aburn G, Gott M, Hoare K. What is resilience? An integrative review of the empirical literature. Journal of advanced nursing. 2016;72(5):980-1000.

19. Connor KM, Davidson JR. Development of a new resilience scale: The Connor-Davidson resilience scale (CD-RISC). Depress Anxiety. 2003;18(2):76-82.

20. Mirarazgar MS. The Role of Resilience in Relative Resistance to Dangerous Social Experiences. Engineering Managemen. 2015;63(8):16-22.

21. Buttram ME, Surratt HL, Kurtz SP. Resilience and syndemic risk factors among African-American female sex workers. Psychology health medicine. 2014;19(4):442-52.

22. Albokordi S, Jahromi MN, Hoseini S, Nikroo M. Relationship between resilience and mental disorders in juvenile offenders of Shiraz Central Prison. Scientific Journal of Kurdistan University of Medical Sciences. 2012;3(17):43-50.

23. Bahmani B, Javadi MH, Khalilzadeh N, Mehraban S. The effectiveness of training resiliency skills on soldier's mental heath. J Psychol Psychiatry. 2018;5(4):78-86.

24. Sharma M, Rush SE. Mindfulness-based stress reduction as a stress management intervention for healthy individuals: a systematic review. Journal of evidence-based complementary alternative medicine. 2014;19(4):271-86.

25. Zahra ST, Riaz S. Mindfulness and resilience as predictors of stress among university students. Journal of Postgraduate Medical Institute (Peshawar-Pakistan) 2018, 32(4).

26. Piri-Kamrani M, Dehghan F, Bashiri H. The Effectiveness of Stress Management Skills Training on Perceived Stress and Resiliency of Women with Multiple Sclerosis. Journal of Health Care. 2016;17(4):319-28.

27. Madani N, Atashpour D, Mousavi D. The Effect of Group-Based Mindfulness-Based Training on the Symptoms of Obsessive-Compulsive Disorder in Isfahan Women. Magazine of New Findings in Psychology. 2010;5(15):57-71.

28. Shapiro SL, Wang MC, Peltason EH. What is mindfulness, and why should organizations care about it. Mindfulness in Organizations 2015:17-41.

29. Pillay D. Positive affect and mindfulness as predictors of resilience amongst women leaders in higher education institutions. SA Journal of Human Resource Management. 2020;18:10.

30. Grant L, Kinman G. Enhancing wellbeing in social work students: Building resilience in the next generation. Social work education. 2012;31(5):605-21.

31. Golpour CR, Mohammad AZ. The efficacy of mindfulness based stress reduction on mindfulness and assertiveness of students with test anxiety. Journal of school psychology. 2012;1(3):825-100.

32. Sedghi P, Cheraghi A. The Effectiveness of The Mindfulness Training on Psychological Well-Being and Resiliency of Female-Headed Household. Family Research. 2019;14(4):549-62. 
33. Izai S, Neama TM. The effectiveness of mindfulness therapy in quality of life among patients with MS. J Clin Psychol. 2017;11(42):37-46.

34. Alberts HJ, Hülsheger UR. Applying mindfulness in the context of work: Mindfulness-based interventions. 2015.

35. Sancho M, Gracia MD, Rodríguez RC, Mallorquí-Bagué N, Sánchez-González J, Trujols J, Sanchez I, Jimenez-Murcia S, Menchon JM. Mindfulness-based interventions for the treatment of substance and behavioral addictions: a systematic review. Frontiers in psychiatry. 2018;9:95.

36. Nila K, Holt DV, Ditzen B, Aguilar-Raab C. Mindfulness-based stress reduction (MBSR) enhances distress tolerance and resilience through changes in mindfulness. Mental Health Prevention. 2016;4(1):36-41.

37. Hwang WJ, Lee TY, Lim K-O, Bae D, Kwak S, Park H-Y, Kwon JS. The effects of four days of intensive mindfulness meditation training (Templestay program) on resilience to stress: a randomized controlled trial. Psychology health medicine. 2018;23(5):497-504.

38. Zarnaqash M, Honarmand M. The Effect of Mindfulness-Based Stress Reduction Therapy on Quality of Life and Resiliency of Spouses of Veterans. Psychological methods models. 2016;7(23):83-97.

39. Bahreini Z, Sanagouye-Moharer G. The Effectiveness of Mindfulness-based Stress Reduction Therapy on Resilience and Self-Discrepancy among Female Patients with Systemic Lupus Erythematosus. SALAMAT IJTIMAI (Community Health). 2019;6(4):406-14.

40. Solati K. The efficacy of mindfulness-based cognitive therapy on resilience among the wives of patients with schizophrenia. Journal of clinical diagnostic research: JCDR. 2017;11(4):VC01.

41. Taghizadeh H, Taghizadeh F, Fathi M, Reihani P, Shirdel N, Rezaee SM. Drug use and high-risk sexual behaviors of women at a drop-in center in Mazandaran Province, Iran, 2014. Iranian journal of psychiatry and behavioral sciences 2015, 9(2).

42. Pedersen ER, Tucker JS, Kovalchik SA. Facilitators and barriers of drop-in center use among homeless youth. J Adolesc Health. 2016;59(2):144-53.

43. Abdi F, Sh B, Ahadi H, Sh K. Psychometric properties of the Connor-Davidson Resilience Scale (CDRISC) among women with breast cancer. Journal of Research in Psychological Health. 2019;13(2):81-99.

44. Mousavi SA, Zare-Moghaddam A, Gomnam A, Hasani F. Mindfulness from theory to therapy. Rooyesh-e-Ravanshenasi Journal (RRJ). 2019;8(1):155-70.

45. Galante J, Dufour G, Vainre M, Wagner AP, Stochl J, Benton A, Lathia N, Howarth E, Jones PB. A mindfulness-based intervention to increase resilience to stress in university students (the Mindful Student Study): a pragmatic randomised controlled trial. The Lancet Public Health. 2018;3(2):e7281.

46. Azad E, Ahmadi T. Effect of mindfulness-based training on quality of life and resilience of chemical warfare disabled veterans in Sardasht, Iran. Neuropsychiatria i Neuropsychologia. 2019;14(3-4):49.

47. Seyf Hosseini A, Asadi J, Sanagoo A, Khajvandkhoshly A. Comparison of Schema Therapy Based on Group Therapy and Mindfulness - Based Stress Reduction on resiliency in mothers of children with 
cancer. Medical Journal of Mashhad University of Medical Sciences. 2019;62:411-20.

48. Hokmabadi ME, Kalantar A, Bigdeli I, Rezapoor Lakani S, Razaghi Kashani S. Examining the effectiveness of Mindfulness based cognitive therapy (MBCT) on increasing resilience of war injured veterans. European Online Journal of Natural Social Sciences. 2018;7(2):471-7.

49. Taherifard M, Mikaeili N. The effectiveness of cognition-based mindfulness therapy on social anxiety, resilience and emotion regulation in women victims of domestic violence. Thought Behavior in Clinical Psychology. 2019;13(51):19-26.

50. Mozaffari V. Effectiveness of Cognitive Mindfulness-based-Therapy on Resilience and Emotional Control of Psychiatric Veteran's Wives. Iranian Journal of War Public Health. 2019;11(2):61-6.

51. Fattahi S, Deldadeh Moghaddam M, Taghavi F. Mindfulness Education on Resilience and Happiness of Mothers with Children with Learning Disabilities. Middle Eastern Journal of Disability Studies. 2016;9(6):1-6.

52. Aghagdi P, Golparvar M, Aghaei A, khayatan F. The effect of mindfulness-centered treatment and emotional therapy on depression and resilience of women affected by spousal breach. Community health. 2018;12(1):1-11.

53. Dyrbye LN, Shanafelt TD, Werner L, Sood A, Satele D, Wolanskyj AP. The impact of a required longitudinal stress management and resilience training course for first-year medical students. J Gen Intern Med. 2017;32(12):1309-14.

54. Sünbül ZA, Güneri OY. The relationship between mindfulness and resilience: The mediating role of self compassion and emotion regulation in a sample of underprivileged Turkish adolescents. Personality Individ Differ. 2019;139:337-42.

55. Danga L, Korb KA. The effect of treatment diffusion on educational experimental designs. Benin Journal of Educational Studies. 2014;23:29-37. 